\title{
El valor social como factor estratégico en la gestión patrimonial y turística: el caso del sitio patrimonio de la humanidad Cueva de Altamira (España)
}

\author{
Eva Parga Dans* Pablo Alonso González** \\ Instituto de Productos Naturales y Agrobiología (IPNA-CSIC) (España) \\ Raimundo Otero Enríquez**** \\ Universidade da Coruña (España) \\ David Barreiro**** Felipe Criado Boado***** \\ Instituto de Ciencias del Patrimonio - Incipit-CSIC (España)
}

\begin{abstract}
Resumen: La dimensión social del valor se ha convertido en una piedra angular del debate sobre conservación, gestión y sostenibilidad turísticas en relación al patrimonio cultural. El presente artículo examina el papel del valor social en la gestión patrimonial y promoción turística a través del caso de la Cueva de Altamira como lugar Patrimonio de la Humanidad UNESCO mediante el análisis de las perspectivas de colectivos no expertos en la gestión del patrimonio. Para ello, se realizaron dos encuestas, una dirigida a visitantes (1047 cuestionarios válidos), y otra a la población española como comunidad anfitriona (1000 cuestionarios válidos). Los resultados muestran cómo estos agentes interpretan el valor de existencia, estético, económico y de legado de formas divergentes a la de los expertos, profundizando en la compleja relación entre la promoción y preservación patrimonial, y ampliando el debate sobre cómo el valor social puede contribuir a fortalecer la imagen internacional y nacional de los destinos patrimoniales ante el futuro incierto del mercado turístico global.
\end{abstract}

Palabras Clave: Valor social; Sitio Patrimonio de la Humanidad de Altamira; Turismo cultural; Preservación patrimonial; Perspectiva comunitaria; Destino turístico.

Social value as a strategic factor in heritage and tourist management: The case of the Altamira Cave World Heritage Site (Spain)

Abstract: The social dimension of value has become a cornerstone of the debate about tourism conservation, management and sustainability in relation to cultural heritage. This article examines the role of social value in heritage management and tourism promotion through the case of the Altamira Cave as a UNESCO World Heritage site by analysing the perspectives of non-expert actors in heritage management. To do this, two surveys were conducted, one aimed at visitors (1047 valid questionnaires) and the other at the Spanish population at large as the host community (1000 valid questionnaires). The results show how these agents interpret the existence, aesthetic, economic and legacy value in ways that differ from those of the experts, deepening the complex relationship between heritage promotion and preservation, and broadening the

Instituto de Productos Naturales y Agrobiología (IPNA-CSIC); E-mail: eva.parga.dans@ipna.csic.es; https://orcid.org/0000$-0002-0095-2963$

* Instituto de Productos Naturales y Agrobiología (IPNA-CSIC) (España); E-mail: pablo.alonso.gonzalez@ipna.csic.es; https://orcid.org/0000-0002-5964-0489

*** Universidade da Coruña (España); E-mail: raimundo.otero@udc.es; https://orcid.org/0000-0002-8074-3765

**** Instituto de Ciencias del Patrimonio - Incipit-CSIC (España); E-mail: david.barreiro@incipit.csic.es; http://orcid.org/0000$-0001-9963-1555$

***** Instituto de Ciencias del Patrimonio - Incipit-CSIC (España); E-mail: felipe.criado-boado@incipit.csic.es; https://orcid. org/0000-0003-4235-706X 
debate on how social value can contribute to strengthen the international and national image of heritage destinations in the face of the uncertain future of the global tourism market.

Keywords: Social value; Altamira World Heritage Site; Heritage tourism; Heritage preservation; Stakeholder perspective; Tourism destination.

\section{Introducción}

Con anterioridad a que la crisis del Covid-19 paralizase la actividad turística a nivel global, la literatura científica identificó el turismo cultural, y más específicamente el turismo patrimonial, como el segmento de más rápido crecimiento en el mercado turístico del siglo XXI (Prats, 2011). Las estadísticas de la Organización Mundial del Turismo así lo corroboran, estableciendo que cuatro de cada diez turistas eligen su destino de acuerdo a factores culturales, y estimando un aumento del turismo cultural en un 15\% a finales de siglo (OMT, 2018). El patrimonio cultural es un activo estratégico para el desarrollo económico, social y territorial, y la Comisión Europea llegó a declarar el Año Europeo del Patrimonio Cultural en 2018, haciendo hincapié en la necesidad de una agenda política para la gestión del patrimonio.

Desde las ciencias humanas y sociales se ha explorado ampliamente la controversia asociada a la gestión del patrimonio, es decir, a la necesidad de su preservación, conservación y/o protección a la vez que la de favorecer su difusión, promoción y disfrute (Parga Dans, 2019). Tradicionalmente, disciplinas como la historia, arqueología, derecho, economía, sociología y, más recientemente, los estudios de mercadotecnia, organizativos y de gestión, así como los estudios del patrimonio, se han centrado en este debate (Timothy, 2018, Alonso González, 2017, Parga Dans y Alonso González, 2020), adquiriendo mayor complejidad en elementos declarados Sitios Patrimonio de la Humanidad (en adelante SPH) por la UNESCO (Tucker y Carnegie, 2014). Los SPH se designan siguiendo una serie de directrices establecidas por la Convención del Patrimonio Mundial de la UNESCO, que atienden a diversos factores determinantes de la declaración de su valor universal excepcional mediante la evaluación de especialistas (Bertacchini, Liuzza, y Meskell, 2017). Tal reconocimiento funciona de manera similar a una marca de destino turístico, suponiendo un reclamo o atractivo turístico a nivel internacional (Ryan y Silvanto, 2010) y transformando el valor simbólico de estos espacios (Michelson y Paadam, 2016).

Sin embargo, el reconocimiento de un SPH en función de los antedichos criterios técnicos, puede no ser interpretada de la misma forma por otros grupos de interés que conviven en estos espacios, por ejemplo, la comunidad local y visitantes, ocasionando controversias en cuanto a su gestión (Parkinson, Scott, y Redmond, 2016). En este ámbito, la dimensión de valor social del patrimonio (en adelante VSP) adquiere especial relevancia. Recientemente, Jones ha definido el VSP como "el apego colectivo a un lugar, incorporando significados y valores que son importantes para una comunidad" (2017, p. 22). Desde esta perspectiva, el VSP se entiende como una dimensión dinámica en relación al apego colectivo, significado o valor que diferentes grupos de personas otorgan al patrimonio (Prats, 2003). El VSP no puede comprenderse como una categoría fija o estable, sino como un proceso que requiere el reconocimiento de las "ontologías múltiples del patrimonio", de las diferentes perspectivas que van más allá de las de los especialistas (Alonso González, 2016). Por tanto, la consideración del VSP como categoría analítica implica un desafío académico, pues requiere, además de su teorización, una puesta en práctica y una implementación (Díaz-Andreu, 2017).

Hasta la fecha, la investigación no ha dado cuenta de la controversia entre la conservación y la promoción turística desde la perspectiva del VSP en SPH. Por ello, el objetivo de este trabajo es caracterizar el VSP en Altamira, localizada en el municipio cántabro de Santillana del Mar (España) y declarada SPH en 1985, posteriormente ampliado a Cueva de Altamira y Arte Rupestre Paleolítico de la Cornisa Cantábrica en 2008. Este caso de estudio es paradigmático debido a la histórica controversia entre quienes defienden el cierre de la cueva a visitantes para asegurar su preservación futura, y los que apoyan su reapertura para su disfrute y explotación turística presente. Precisamente por ello, la Subdirección de Museos Estatales del Ministerio de Cultura de España, encargó al Instituto de Ciencias del Patrimonio (Incipit) del CSIC el Proyecto "Valor Social de Altamira". Este proyecto se realizó entre 2012 y 2014 como parte del "Programa de Investigación para la Conservación Preventiva y Régimen de Acceso de la Cueva de Altamira" coordinado por el IPCE, y sus resultados informaron la postura final del Ministerio sobre ese problema ${ }^{1}$. Esta polémica nos permite explorar la dimensión del VSP con respecto a la lógica de los SPH como destinos turísticos, realizando una contribución teórica y práctica 
para su gestión y avanzando en el conocimiento en este ámbito teórico en los estudios del turismo y el patrimonio. Para ello, realizamos dos encuestas, una dirigida a visitantes ( $\mathrm{n}=1047$ cuestionarios válidos) y otra a la población española como comunidad anfitriona de este SPH ( $\mathrm{n}=1000$ cuestionarios válidos). Ambos colectivos son considerados como no expertos en la toma de decisiones sobre patrimonio cultural. Los resultados muestran cómo estos agentes interpretan el VSP, profundizando en la compleja relación entre la promoción y preservación patrimonial, y ampliando el debate sobre cómo el valor social puede contribuir a fortalecer la imagen internacional y nacional de los destinos patrimoniales ante el futuro incierto del mercado turístico global.

\section{Marco teórico}

El rápido crecimiento del turismo en SPH a principios del siglo XXI es resultado de una compleja relación entre la oferta turística patrimonial y la interpretación de estos destinos por parte de la demanda (Poria, Reichel, y Cohen, 2013). Múltiples investigaciones han conectado esta relación con la cuestión de la gestión patrimonial (Bourdeau, Gravari-Barbas, y Robinson, 2018; Martín Ríos y Parga Dans, 2016a). La declaración de qué es patrimonio y qué no lo es representa la visión de ciertas élites y profesionales que poco tiene que ver con la visión de la mayoría de la población (González-Ruibal, Alonso González, y Criado-Boado, 2018; Parga Dans et al., 2016), esto es, una serie de criterios científicos, históricos o culturales establecidos por un grupo de especialistas dominantes en la toma de decisiones patrimoniales. Diversas investigaciones han mostrado, sin embargo, que la exclusión de otras partes interesadas en el proceso de patrimonialización puede generar un cuestionamiento del valor, autenticidad o apego colectivo a estos espacios (Benito Del Pozo y Alonso González, 2012), amenazando, incluso, su sostenibilidad a medio y largo plazo (Alonso González, Macías Vázquez, y Fernández Fernández, 2017; Martín Ríos y Parga Dans, 2016b).

El VSP adquiere, por tanto, relevancia analítica en el debate sobre la conservación y promoción patrimonial. El VSP no deriva de los atributos asignados a un sitio patrimonial, sino de la percepción de las diferentes partes interesadas (Jones, 2017). Carta de Burra (Icomos Australia, 1999 [1979]) reconocía la importancia de la dimensión social para la gestión patrimonial, entendida como la suma de los valores de varios grupos sociales, enfatizando que son las comunidades contemporáneas las que atribuyen significados y valores al patrimonio. Desde entonces, emerge una discusión en el área de los Estudios del Patrimonio sobre la necesidad de profundizar en el VSP (Araoz, 2011). Y aunque existe cierto consenso sobre la necesidad de implicar a diferentes colectivos en la gestión patrimonial, su implementación continúa siendo un desafío (Díaz-Andreu, 2017)

En el ámbito de los Estudios Turísticos la noción de valor asociado a SPH y marca de destino adquieren relevancia estratégica. Michelson y Paadam (2016) exploran cómo a través del valor simbólico del patrimonio se construyen marcas de destino turístico reforzadas por la actividad socioeconómica que se genera en los espacios urbanos en torno a este valor simbólico. Paralelamente, Chen y Chen (2010) evalúan la marca de destino patrimonial en relación a la calidad de la experiencia y los servicios turísticos ofrecidos a visitantes. Recientemente, Ramires et al. (2018) analizan el valor patrimonial en relación al gasto turístico, mientras Parga Dans y Alonso González (2017) evalúan el efecto multiplicador del gasto turístico en el PIB autonómico. Sin embargo, todas estas investigaciones divergen en sus conclusiones: algunos estudios refuerzan la relevancia estratégica de SPH como atractivo turístico (Carter, Jolliffe, y Baum, 2001); otros consideran dicho atractivo turístico exagerado (Hall y Piggin, 2002). Tal controversia ha conducido a una crítica estructural de la noción de valor universal como principio fundamental de los SPH, analizando las tensiones sociales que despierta la declaración de la UNESCO (Alonso González, 2017; Tucker y Carnegie, 2014).

De todo este debate teórico se desprende la necesidad de incorporar diversas aproximaciones disciplinares a casos de estudio específicos que aborden la percepción de diferentes colectivos para el establecimiento de una serie de pautas útiles respecto a la conservación, gestión y promoción de SPH (Jansen-Verbeke, 2016). La noción de VSP resulta fundamental para comprender el atractivo y la problemática inherente a SPH como marca de destino turístico. Para la construcción de una categoría analítica sobre VSP nos basamos en el enfoque iniciado por Goulding (2000), quien sustentó la autenticidad del patrimonio como construcción social mediante tres perfiles de visitantes: los buscadores de experiencia existencial, los que asocian autenticidad a estética, y los que persiguen una experiencia social. También retomamos el reciente estudio de Parga Dans y Alonso González (2019), quienes conceptualizan el apego colectivo a SPH a través de cuatro dimensiones del valor patrimonial: existencia, estética, economía y legado. Todas estas dimensiones configuran el VSP. 


\subsection{Valor de existencia}

El patrimonio cultural no es algo que posea un valor intrínseco o inherente (Poulios, 2010). Como enfatiza la Carta de Burra (Icomos Australia, 1999 [1979]), una gestión patrimonial sostenible debe comenzar por comprender su existencia. El reconocimiento de un lugar patrimonial por parte de diferentes agentes o colectivos, más allá de su declaración institucional, puede legitimar un interés social y un valor de existencia (Darvill, 1994) o un valor histórico (Mason y Avrami, 2002). El reconocimiento de la existencia de un lugar patrimonial implica una capacidad colectiva de atribuir significado o un valor a éste, justificando la necesidad de su gestión. El trabajo de Goulding (2000) caracteriza a un perfil de visitantes que buscan experiencias turísticas basadas en el valor de existencia, es decir, en el reconocimiento contemporáneo de la cultura material, el patrimonio y los objetos del pasado. De la misma forma, el trabajo de Parga Dans y Alonso González (2019) propone que el valor de existencia es el conjunto de percepciones, expectativas y conocimientos sobre un sitio específico a través de un colectivo no experto, incluidos visitantes y comunidades locales.

\subsection{Valor estético}

Una vez reconocido el valor de existencia del patrimonio es posible avanzar hacia su valor estético. La dimensión estética del patrimonio se asocia con la función simbólica del pasado en el presente (Parga Dans y Alonso González, 2019). En este sentido, Goulding (2000) explica el colectivo que valora el patrimonio cultural a través de la dimensión estética, busca experiencias turísticas contemporáneas basadas en la comprensión del pasado a través de las artes, la arquitectura o la artesanía. En este sentido, la dimensión estética del patrimonio se asocia con la autenticidad percibida (Viu, Fernández, y Caralt, 2008), buscando entender el presente mediante la cultura material, lugares y objetos de épocas anteriores.

\subsection{Valor económico}

La dimensión económica del patrimonio es controvertida, pues a la vez que es reconocida como factor estratégico para el desarrollo territorial presenta desafíos con respecto a su conservación y sostenibilidad (Mason y Avrami, 2002). Específicamente, el valor económico de SPH ha sido abordado desde diferentes puntos de vista, atendiendo a su impacto directo e indirecto en el PIB regional (Parga Dans y Alonso González, 2017), o mediante el nivel de satisfacción de los servicios turísticos en relación con el gasto turístico (Chen y Chen, 2010). En términos generales, los estudios que abordan el valor económico del patrimonio muestran el potencial de su promoción, pero también cuestionan la dimensión cuantitativa, pues es necesaria ponerla en relación con la sostenibilidad turística del espacio patrimonial (Parga Dans y Alonso González, 2019).

\subsection{Valor de legado}

Dado que el patrimonio cultural tiene un valor de existencia (se reconoce como tal) y un valor estético o artístico (suscita percepciones sensoriales o simbólicas sobre el pasado en el presente), y se considera un recurso (genera gastos e ingresos), es probable que se planteen modelos de gestión para su preservación futura o de legado (Graham, Ashworth, y Tunbridge, 2016). Por tanto, la necesidad de equilibrar la relación entre conservación y promoción patrimonial en el presente para el futuro hace referencia al valor de legado. Aunque la capacidad de preservar la herencia patrimonial ha sido abordada en múltiples sociedades, períodos y culturas, la cuestión de quién o qué colectivos deberían tener la potestad en la toma de decisiones sobre SPH y para quién, continúa siendo fuente de controversia (ICOMOS, 2019).

\section{Metodología}

\subsection{Contexto de investigación}

La Cueva de Altamira se descubrió fortuitamente en 1868. Desde entonces comenzó un debate científico y social acerca de su autenticidad, cuestionada en el ámbito académico durante décadas. En 1902, un estudio francés confirmó la autenticidad de las pinturas y su origen prehistórico (Cartailhac, 1902). Los resultados de esta investigación posicionaron a Altamira como lugar único y emblemático del patrimonio cultural, arqueológico, e histórico del Paleolítico Superior; un icono mundial para comprender el origen de la humanidad y el arte con pinturas y grabados de más de 15.000 años. Durante los 70, Altamira se convirtió en un importante destino turístico que atraía más de 150.000 visitantes al año. La excelente calidad y estado de las pinturas hace que esta cueva sea considerada una obra maestra de la humanidad, también conocida como la "Capilla Sixtina del arte rupestre europeo" (Schabereiter-Gurtner, Saiz-Jimenez, Piñar, Lubitz, y Rölleke, 2002). Sin embargo, la elevada afluencia de visitantes abrió un debate sobre la necesidad de implementar un programa de conservación. 
La cueva se cerró temporalmente en 1977, tras una alerta de elevados niveles de $\mathrm{CO}^{2}$ por parte de la comunidad científica que amenazaba el paulatino deterioro de las pinturas a causa de las más de 4.000 visitas diarias. En 1979 el Ministerio de Cultura asumió la gestión de la cueva, reabriéndola en 1982 con un cupo de 11.300 visitas al año. Este límite de acceso derivó en una larga lista de espera que alcanzó los tres años. En el año 2001, los Reyes de España inauguraron el Museo y la "Neo-cueva" (una réplica a escala real de la cueva), permitiendo una forma alternativa de acceso a este SPH. En 2002 la cueva se cerró nuevamente al público tras la aparición de una serie de microorganismos en las pinturas similares a los encontrados en la cueva de Lascaux, Francia. Pese al cierre de la cueva, el Museo y la "Neo-cueva" lograron atraer un promedio de 250.000 visitas anuales durante el período 2002-2019, siendo el segundo museo público más visitado en España y un impulsor estratégico para el desarrollo regional cántabro.

A pesar del estado aparente de equilibrio entre la conservación patrimonial y la promoción turística de Altamira, el debate sobre la reapertura de la cueva no está resuelto (Barreiro et al., 2018). Diferentes posturas continúan enfrentadas, entre las que se encuentran el discurso científico y técnico que alerta sobre el impacto de la presencia humana en la conservación de las pinturas, frente al discurso empresarial, político y social de la localidad de Santillana del Mar, quienes reclaman un rol activo en la toma de decisiones sobre la gestión de este SPH, así como su promoción (Barreiro y Criado-Boado, 2015). Esta controversia llevó al gobierno español a sentar las bases científicas de un programa que garantizase la conservación adecuada de la cueva y un régimen de acceso a visitantes.

En 2012 se puso en marcha el Programa de Investigación para la Conservación Preventiva y Régimen de Acceso a la Cueva de Altamira impulsado desde la Secretaría de Estado de Cultura del Ministerio de Educación, Cultura y Deporte, previo acuerdo del Patronato del Museo de Altamira. Dicho Programa se emprende con el objetivo de determinar el impacto que la presencia humana tiene sobre la conservación de las pinturas de la cueva, y decidir si es compatible un régimen de visitas con una adecuada conservación. La originalidad de esta iniciativa es que contempla, por primera vez, un estudio sobre el VSP, incorporando a un equipo de especialistas en el ámbito de la sociología y la antropología. En él, las ciencias sociales desempeñan un papel estratégico en la valorización y gestión patrimonial mediante la incorporación de otros colectivos en el proceso de toma de decisiones. El presente manuscrito presenta los resultados de la investigación sobre VSP en SPH, con el objeto de facilitar el desarrollo de directrices políticas y recomendaciones para resolver la histórica controversia de la gestión de Altamira.

\subsection{Recopilación de datos}

La recopilación de datos implicó la realización de dos encuestas dirigidas a diferentes colectivos no expertos (a los visitantes de Altamira, y otra al conjunto de la población española), lo cual resulta especialmente útil para abordar la multidimensionalidad del VSP en Altamira como SPH. La encuesta a visitantes incluye un total de 35 preguntas/variables distribuidas en cuatro bloques temáticos que identifican el VSP: (1) el valor de existencia (expectativas y motivaciones previas al viaje); (2) el valor estético (impacto sensorial-artístico del destino, su evaluación y satisfacción derivada); (3) el valor económico (información del viaje y gasto de los visitantes); (4) y el valor de legado (opiniones, actitudes y comportamientos de los visitantes respecto a la promoción-preservación de Altamira). Por último, el cuestionario incorpora una serie de variables destinadas a identificar el perfil sociodemográfico de visitantes. La encuesta fue realizada in situ en la salida del museo de Altamira y dirigida a una muestra aleatoria simple, teniendo en cuenta el número total de visitantes del año 2013 (239.829), estratificada por género y edad (con un nivel de confianza del 95\% y error del 3\%, cumpliéndose la condición de partida de que p=q=0,5). Dicha muestra alcanza un total de 1.047 encuestas válidas, que se realizan durante tres temporadas turísticas diferentes (alta, media y baja), entre junio de 2013 y febrero de 2014, de viernes a domingo.

Por otro lado, la encuesta dirigida a la población española incluye 28 preguntas/variables que aportan información sobre los cuatro sub-valores que configuran el valor social de Altamira: (1) de existencia (conocimiento y visibilidad de Altamira); (2) estético (impacto sensorial-artístico de Altamira); (3) económico y (4) de legado (opiniones acerca de la dicotomía apertura-cierre de la cueva, preferencias sobre la financiación y toma de decisiones sobre la gestión). Esta encuesta, de formato telefónico, se sustenta en una muestra no probabilística dirigida a la población española mayor de 18 años, formada por 1000 cuestionarios válidos realizados durante el período mayo-septiembre de 2014, de viernes a domingo. Dicha muestra se desglosa, a su vez, en cuotas proporcionales atendiendo al volumen de población tanto de la Comunidad Autónoma de Cantabria (donde se encuentra Altamira), como de las siete Nomenclaturas de las Unidades Territoriales Estadísticas (en adelante NUTS) que abarcan el conjunto del territorio español, y diseñadas por la Unión Europea con fines estadísticos (Figura 1). 
Estas divisiones geográficas son fundamentales a la hora de evaluar si la proximidad residencial a un $\mathrm{SPH}$ altera las desviaciones respecto de los resultados generales de la encuesta.

\section{Figura 1: NUTS españolas y Comunidad Autónoma de Cantabria.}

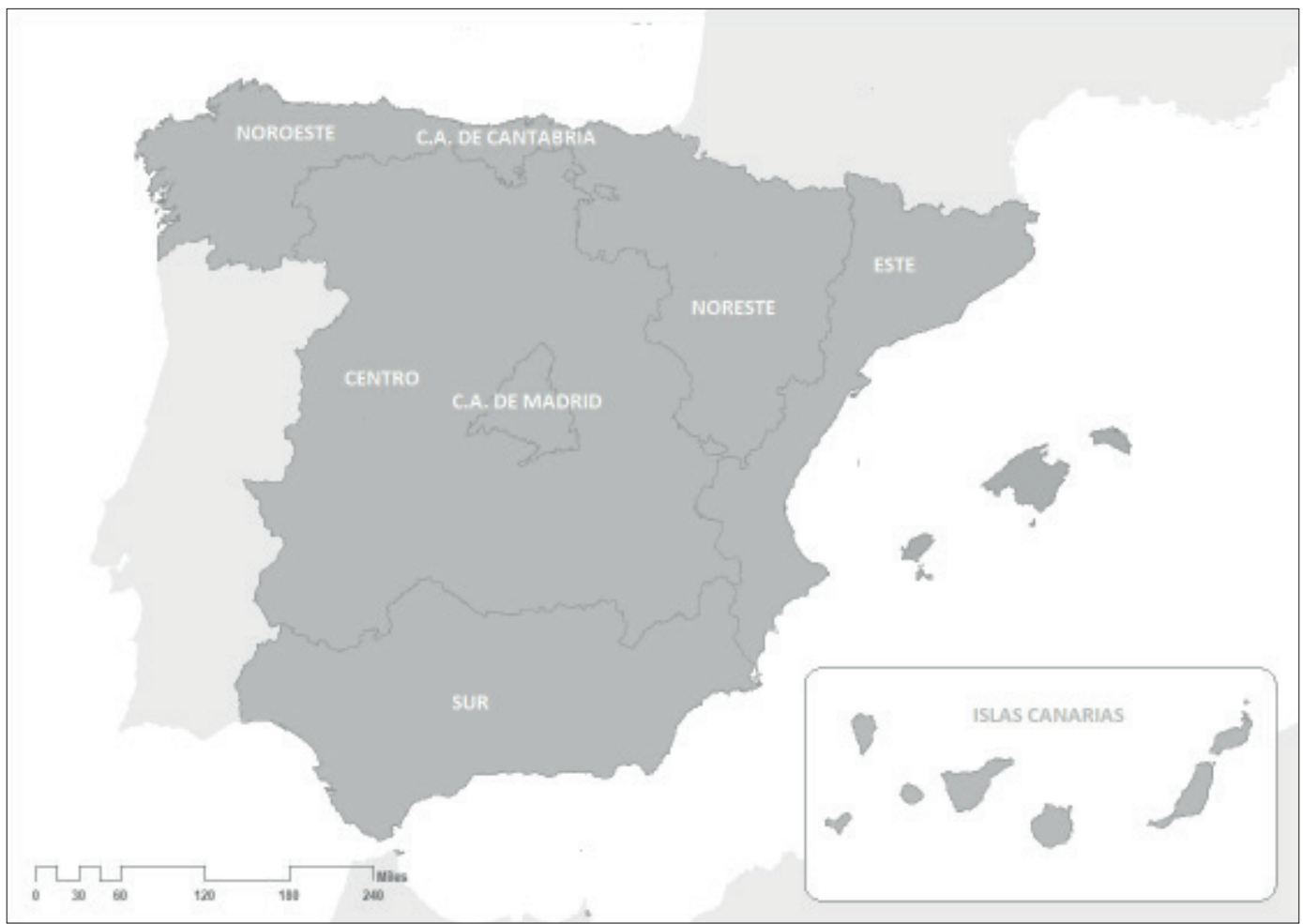

Fuente: Elaboración propia.

\subsection{Análisis de los datos}

El VSP se categoriza en la presente investigación a través del sub-valor de existencia, estético, económico y de legado, los cuales a su vez se categorizan mediante una variable específica o demostrativa de cada uno de los bloques temáticos diseñados con esta finalidad. Posteriormente, cada una de las dimensiones del VSP ha sido cruzada con variables sociodemográficas (género, edad, nivel educativo, situación laboral y tipo de ocupación) y geográficas (NUTS). Específicamente, aplicamos un análisis simple de correspondencias (en adelante ACS), o un análisis de componentes principales categórico (en adelante CATPCA) para el sub-valor de existencia, estético y de legado, teniendo en cuenta que la mayor parte de las variables de referencia son categóricas. Ambas técnicas, además de identificar correspondencias entre diversas variables, permiten desarrollar una interpretación visual de dicha correlación. Para ello, realizamos un mapa perceptual o gráfico de dispersión de dos dimensiones, siempre partiendo de variables sociodemográficas y geográficas que mostrasen una correspondencia significativa con respecto a la variable de contraste seleccionada para representar cada uno de los sub-valores (atendiendo al valor de $\chi^{2}$ y nivel de significación asociado al valor de la prueba p. $<0,01$, o p.< 0,05). De esta forma, aumentamos el porcentaje de varianza explicada o el valor de la inercia, concentrándose éstos fundamentalmente en la primera dimensión del mapa perceptual y estableciendo relaciones explicativas entre categorías de variables (Joaristi y Lizasoain Hernández, 2000; Santa-Cruz y López-Guzmán, 2017).

Finalmente, realizamos un análisis de varianza de un factor (en adelante ANOVA) aplicado al sub-valor de legado, con el objetivo de profundizar en la capacidad explicativa del discurso museístico de 
Altamira a la hora de transmitir la problemática en torno a la gestión de este SPH. La técnica ANOVA ha sido frecuentemente aplicada en contextos patrimoniales (e.g., Ramires et al., 2018), para identificar diferencias significativas entre las medias de una variable dependiente cuantitativa y variables independientes cualitativas o categorías de un factor (Hair, Black, Babin, y Anderson, 2010). Específicamente, contrastamos de qué manera los niveles de satisfacción de la vista a Altamira (variable de escala) son significativamente diferentes, en función de dos variables independientes que representan el sub-valor de legado: por un lado, el grado de aceptación de cerrar la cueva para mantener su conservación futura; y, por otro, la capacidad educativa del museo para explicar por qué la cueva está cerrada.

Además, para cada ANOVA realizado, los supuestos estadísticos de homocedasticidad y normalidad se evaluaron mediante la prueba post-hoc de Games-Howell y de Kolmogorov-Smirnov, descartando la igualdad de las varianzas, e ilustrando la significatividad de la relación entre las diferencias de las medias (Hair et al., 2010). En cuanto al sub-valor económico, desarrollamos un estudio específico para evaluar el impacto económico de Altamira sobre el PIB cántabro a partir del gasto de los visitantes, obtenido mediante la síntesis de dos variables descriptivas numéricas: la duración promedio de la estancia en la región cántabra y el gasto medio de la visita a Altamira.

\section{Resultados y discusión}

\subsection{Valor de existencia}

La importancia contemporánea de Altamira tanto para el público visitante como para la población española, muestra el valor de existencia de este SPH. Primero, el complejo museístico de Altamira consigue atraer a un número significativo de visitantes en el presente, a pesar del cierre de la cueva. De hecho, tras la apertura de la "Neo-Cueva" y el Museo en el año 2001, Altamira alcanzó un promedio de 250.000 visitas anuales, superando la cifra histórica de 174.000 visitas a la cueva original registrada en 1973 (Figura 2). Desde entonces, Altamira se posiciona como el segundo museo público más visitado de España, suponiendo un factor estratégico de atracción turística para Cantabria y España (LPPM, 2010).

Figura 2: Datos de visitantes de Altamira (1952-2019).

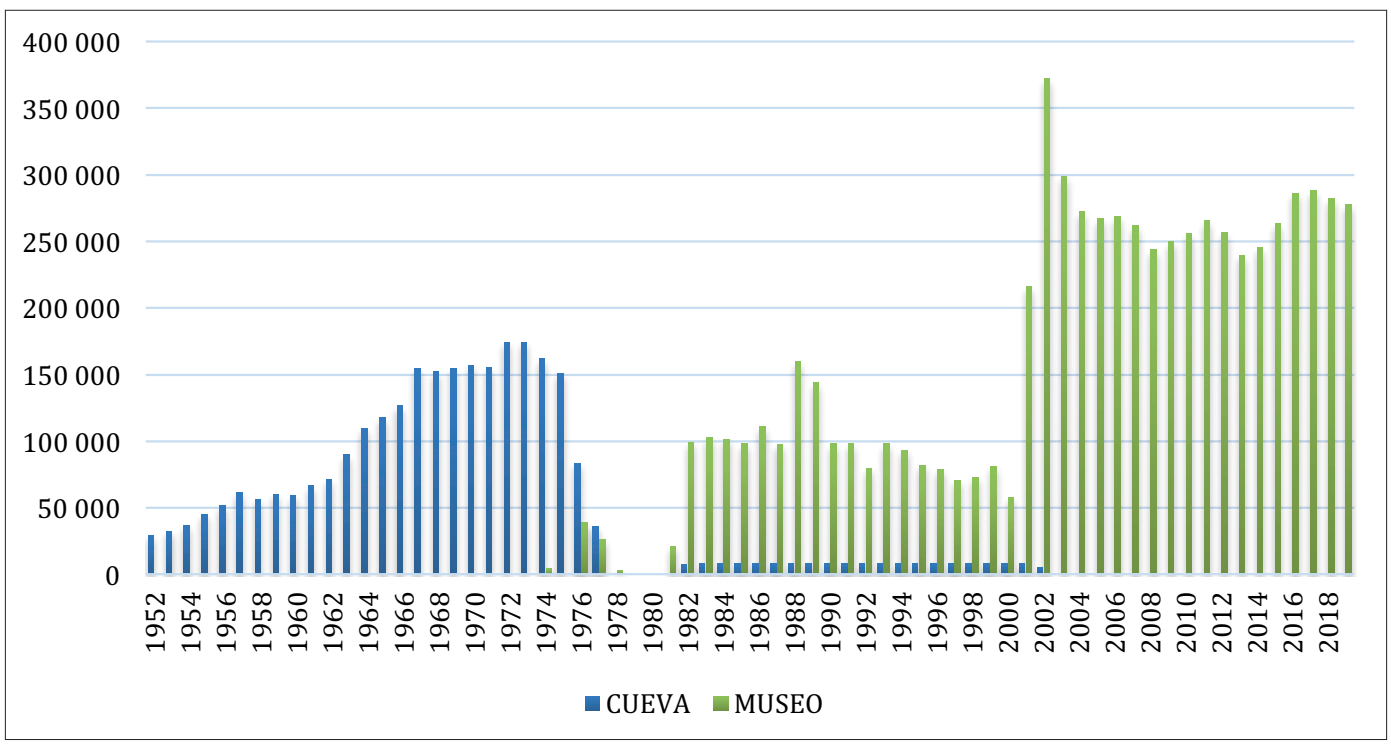

Fuente: Elaboración propia a partir del registro de visitantes del complejo museístico de Altamira.

Segundo, los resultados de la encuesta dirigida a visitantes corroboran el valor de existencia de Altamira en el presente. Así, Altamira es el principal determinante de la organización del viaje para el $60 \%$ del público visitante. Además, el $84 \%$ de los visitantes organizan su desplazamiento sin ninguna 
expectativa de poder acceder a la cueva original y, de éstos, el 71\% espera encontrar una buena réplica de la cueva mediante la visita a la "Neo-Cueva", mostrando un conocimiento sobre la situación actual de este SPH.

Tercero, los resultados de la encuesta a la población española muestran que el 83\% de las personas encuestadas conoce Altamira. Así, existe un amplio reconocimiento social de este SPH, atribuyéndole un valor de existencia y un poder para atraer turistas (Poulios, 2010). El alcance del valor de existencia se caracteriza de manera más precisa considerando las variables sociodemográficas de la población encuestada. El análisis de las variables de segmentación muestra que son las personas de entre 40 y 64 años (87.9\%), con estudios universitarios (94.6\%) y ocupaciones relacionadas con educación, artes, cultura o investigación (95.0\%) las que mayoritariamente afirman conocer la existencia de Altamira (Tabla 1).

Este análisis muestra que el nivel educativo discrimina significativamente los niveles más altos y más bajos de conocimiento sobre la existencia de Altamira $\left(\chi^{2}=123,087, p<.001\right)$. Específicamente, en comparación con el $94.6 \%$ de reconocimiento alcanzado por personas con educación universitaria, las de un nivel formativo inferior son las que en menor medida habían oído hablar de la cueva (un $62,1 \%$ manifestaron conocer la existencia de la cueva). Así, un nivel de educación superior implica un mayor valor de existencia, cuestionando el argumento de Petr (2009) sobre la importancia per se de la marca SPH como atractivo turístico. En Altamira podemos concluir que, a mayor nivel de formación y trabajo vinculado con la cultura, mayor conocimiento sobre la existencia del patrimonio.

Tabla 1: Tabla de contingencia (valor de existencia * variables de segmentación).

\begin{tabular}{|c|c|c|c|c|c|c|c|c|c|}
\hline \multicolumn{10}{|c|}{ ¿Ha oído hablar de la cueva de Altamira? } \\
\hline \multirow{2}{*}{\multicolumn{2}{|c|}{$\begin{array}{c}\text { Variables de segmentación } \\
\text { Recuento }\end{array}$}} & \multicolumn{2}{|c|}{ Sí } & \multicolumn{2}{|c|}{ No } & \multicolumn{2}{|c|}{ Total } & \multirow{2}{*}{\multicolumn{2}{|c|}{$\begin{array}{c}\text { Valor de } \\
\text { chi-cuadrado } \\
\text { y nivel } \\
\text { asociado de } \\
\text { significación }\end{array}$}} \\
\hline & & Recuento & $\begin{array}{l}\% \text { de } \\
\text { la fila }\end{array}$ & Recuento & $\begin{array}{l}\% \text { de } \\
\text { la fila }\end{array}$ & Recuento & $\begin{array}{l}\% \text { de } \\
\text { la fila }\end{array}$ & & \\
\hline \multirow{2}{*}{ Sexo } & Hombre & 406 & $84,2 \%$ & 76 & $15,8 \%$ & 482 & $100 \%$ & \multirow{2}{*}{1,165} & \multirow{2}{*}{,280 } \\
\hline & Mujer & 423 & $81,7 \%$ & 95 & $18,3 \%$ & 518 & $100 \%$ & & \\
\hline \multirow{3}{*}{$\begin{array}{l}\text { Edad en } \\
\text { grandes grupos }\end{array}$} & $18-39$ & 278 & $81,0 \%$ & 65 & $19,0 \%$ & 343 & $100 \%$ & \multirow{3}{*}{17,142} & \multirow{3}{*}{, 000} \\
\hline & $40-64$ & 392 & $87,9 \%$ & 54 & $12,1 \%$ & 446 & $100 \%$ & & \\
\hline & 65 o más & 159 & $75,4 \%$ & 52 & $24,6 \%$ & 211 & $100 \%$ & & \\
\hline \multirow{2}{*}{$\begin{array}{l}\text { ¿Su ocupación } \\
\text { actual tiene } \\
\text { alguna } \\
\text { relación con } \\
\text { la educación, } \\
\text { el arte, la } \\
\text { cultura o la } \\
\text { investigación? }\end{array}$} & Sí & 113 & $95,0 \%$ & 6 & $5,0 \%$ & 119 & $100 \%$ & \multirow{2}{*}{13,854} & \multirow{2}{*}{, 000} \\
\hline & No & 716 & $81,3 \%$ & 165 & $18,7 \%$ & 881 & $100 \%$ & & \\
\hline \multirow{4}{*}{$\begin{array}{l}\text { Nivel de } \\
\text { estudios } \\
\text { recodificado }\end{array}$} & $\begin{array}{l}\text { Sin estudios / } \\
\text { Primarios }\end{array}$ & 110 & $62,1 \%$ & 67 & $37,9 \%$ & 177 & $100 \%$ & \multirow{4}{*}{123,087} & \multirow{4}{*}{, 000} \\
\hline & ESO & 36 & $64,3 \%$ & 20 & $35,7 \%$ & 56 & $100 \%$ & & \\
\hline & Bachillerato / FP & 292 & $89,0 \%$ & 36 & $11,0 \%$ & 328 & $100 \%$ & & \\
\hline & $\begin{array}{l}\text { Universitario / } \\
\text { Superiores }\end{array}$ & 370 & $94,6 \%$ & 21 & $5,4 \%$ & 391 & $100 \%$ & & \\
\hline \multirow{4}{*}{$\begin{array}{l}\text { Situación } \\
\text { laboral } \\
\text { recodificada }\end{array}$} & Estudiantes & 33 & $84,6 \%$ & 6 & $15,4 \%$ & 39 & $100 \%$ & \multirow{4}{*}{6,211} & \multirow{4}{*}{,102 } \\
\hline & Ocupados/as & 428 & $87,3 \%$ & 62 & $12,7 \%$ & 490 & $100 \%$ & & \\
\hline & $\begin{array}{l}\text { Jubilados/as } \\
\text { - Pensionistas }\end{array}$ & 201 & $81,0 \%$ & 47 & $19,0 \%$ & 248 & $100 \%$ & & \\
\hline & Desempleados/as & 145 & $81,9 \%$ & 32 & $18,1 \%$ & 177 & $100 \%$ & & \\
\hline
\end{tabular}

Fuente: Elaboración propia. 
Delimitando la región Cántabra y las NUTS españolas, el valor de existencia de Altamira se ilustra desde una perspectiva territorial. Con la excepción de la NUT Islas Canarias (con un 53\% de respuestas afirmativas), más del 75\% de la población de las restantes NUTS afirma conocer la existencia de Altamira. Sobresalen Cantabria y las NUTS del centro peninsular y de Madrid, territorios que muestran porcentajes superiores al 90\%. La proximidad geográfica al complejo museístico de Altamira juega un papel importante en su reconocimiento, factor que explica que la correspondencia entre ambas variables sea significativa $\left(\chi^{2}=36,174 ; \mathrm{p}<.001\right)$.

El CATPCA proporciona una representación visual del comportamiento conjunto de las variables de segmentación y el reconocimiento de la existencia de Altamira. La figura 3 representa, por un lado, los segmentos de población cuyos centroides se aproximan a la categoría "nunca oí hablar de Altamira", los cuales se corresponden con la población mayor de 65 años, principalmente sin estudios o con formación primaria o secundaria, y residente en las Islas Canarias. Por otro lado, una gran cantidad de categorías sociodemográficas y áreas geográficas de España se agrupan en torno al "sí ha oído hablar de la Cueva", lo que demuestra, en síntesis, la fortaleza del valor de existencia de Altamira.

Figura 3: Gráfico de categorías conjuntas (valor de existencia - ¿Ha oído hablar de la cueva de Altamira? * variables de segmentación * unidades territoriales). Autovalor $($ Total $)=3,463 /$ Alfa de Cronbach $($ Total $)=0,871$. Autovalor $($ Dimensión 1) = 2,360 / Alfa de Cronbach $($ Dimensión 1) = 0,692.

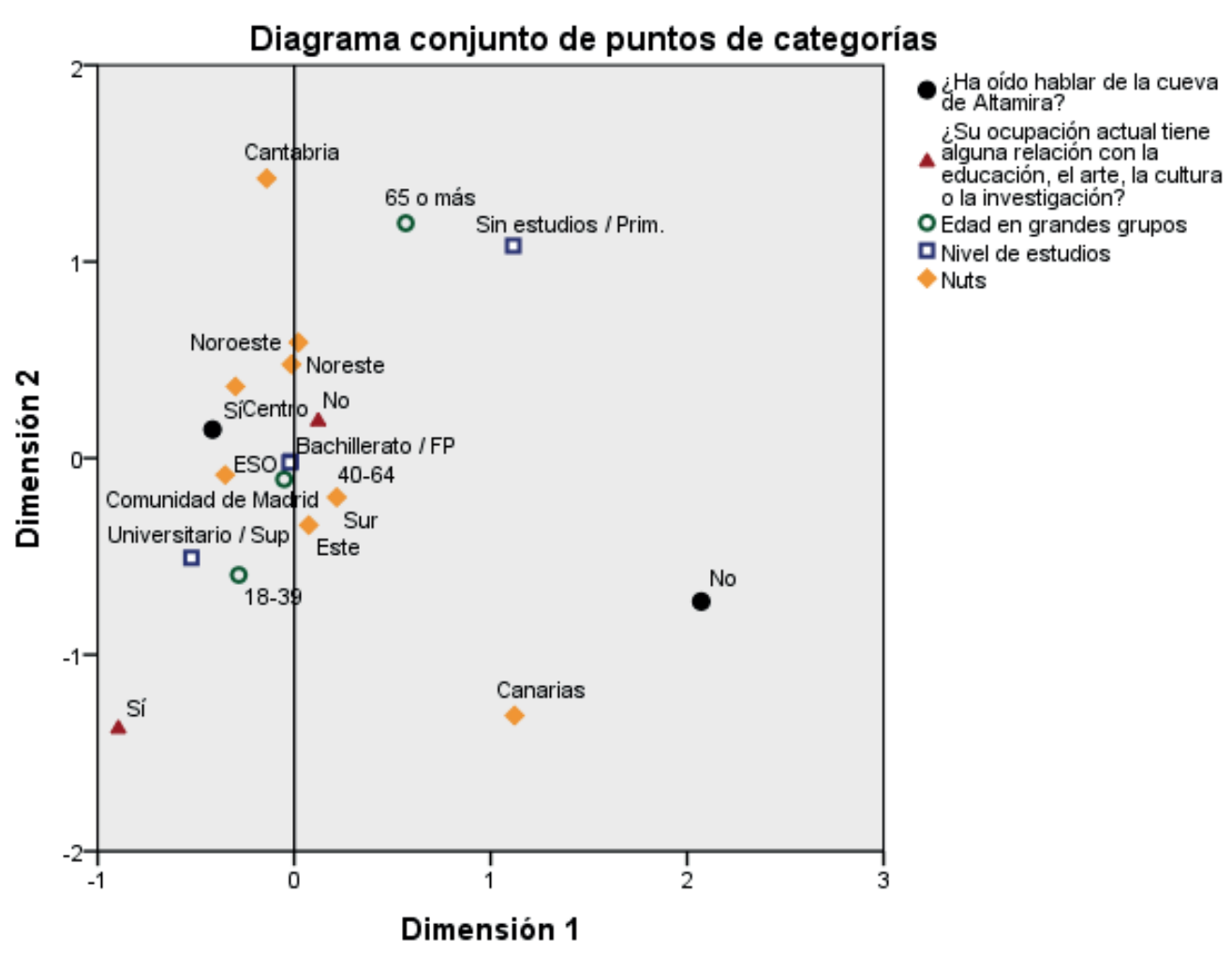

Normalización principal por variable.

Fuente: Elaboración propia.

Profundizando en el conocimiento de la población visitante sobre Altamira, los resultados de la encuesta permiten matizar algunas cuestiones sobre el valor de existencia. El 83,3\% de los visitantes 
afirman que Altamira es un lugar fundamental para comprender o aprender nociones sobre la prehistoria de la humanidad, a pesar de no poder acceder a la cueva y pinturas originales. La visita a Altamira, independientemente del perfil demográfico y procedencia territorial, también contribuye a apuntalar esta dimensión del valor. Más allá de esta generalidad, factores como la proximidad geográfica al complejo museístico y el nivel educativo de la persona juegan un papel decisivo en el reconocimiento de Altamira. Así, el reconocimiento del valor de existencia por parte de visitantes, población española y colectivo experto, quienes en 1985 declararon Altamira SPH, evidencia la importancia del debate social contemporáneo sobre la gestión de este lugar.

Específicamente, varios estudios han demostrado que la actividad turística generada por los SPH supone una oportunidad para aumentar la visibilidad y la demanda de un determinado destino en el mercado global del turismo patrimonial (Adie, Hall, y Prayag, 2017; Ramires et al., 2018). Nuestro estudio demuestra lo contrario: Altamira atrae en mayor medida el interés turístico nacional, puesto que el 86\% de los visitantes son población residente en España. Así, el valor de existencia por parte de la comunidad anfitriona puede ser un factor determinante para reforzar la imagen de los SPH, quienes, a su vez, pueden convertirse en comunidad visitante. Esta cuestión no ha sido investigada en profundidad, motivo por el cual nos parece esencial identificar vínculos de múltiples colectivos no expertos con los SPH.

\subsection{Valor estético}

En cuanto a la dimensión estética del valor, analizamos las percepciones contemporáneas sobre Altamira en relación con la función simbólica del pasado. En este sentido, los resultados de la encuesta muestran que más del 70\% de la población española considera que el elemento más importante de Altamira son las pinturas rupestres, en detrimento de otros factores como la declaración SPH (4,7\%), ser un destino de interés turístico (1,5\%), o una marca nacional o identitaria (1,5\%). Por tanto, además del reconocimiento contemporáneo de la existencia de Altamira por parte de sus visitantes y de la población española, observamos un proceso de atribución de significados vinculados a este lugar patrimonial en conexión con sus pinturas, lo cual configura su valor estético.

Como observamos con el valor de existencia, el reconocimiento del valor estético para la población española conocedora de la existencia de Altamira es muy elevado en todas las NUTS (superior al 68\% en todos los casos). Con la excepción de Cantabria (donde el 44,8\% de su población asume que Altamira tiene múltiples reclamos), el reconocimiento de las pinturas como único factor determinante de la importancia de Altamira no presenta disparidades geográficas, razón por la cual la correspondencia entre la variable geográfica y el valor estético no es significativa $(\chi 2=14,012, \mathrm{p}>0.05)$.

Atendiendo al cruce con las variables de segmentación sociodemográfica, el consenso sobre la importancia de las pinturas es determinante, superando valores por encima del $50 \%$ en todos los casos (Tabla 2). Por el contrario, la categoría de respuesta "ser SPH" como factor asociado a la importancia de Altamira obtiene un volumen de respuesta claramente inferior en todos los ítems contemplados (que, salvo en el caso de los estudiantes, no supera el $10 \%$ ). 
Tabla 2: Tabla de contingencia (valor de existencia * variables de segmentación).

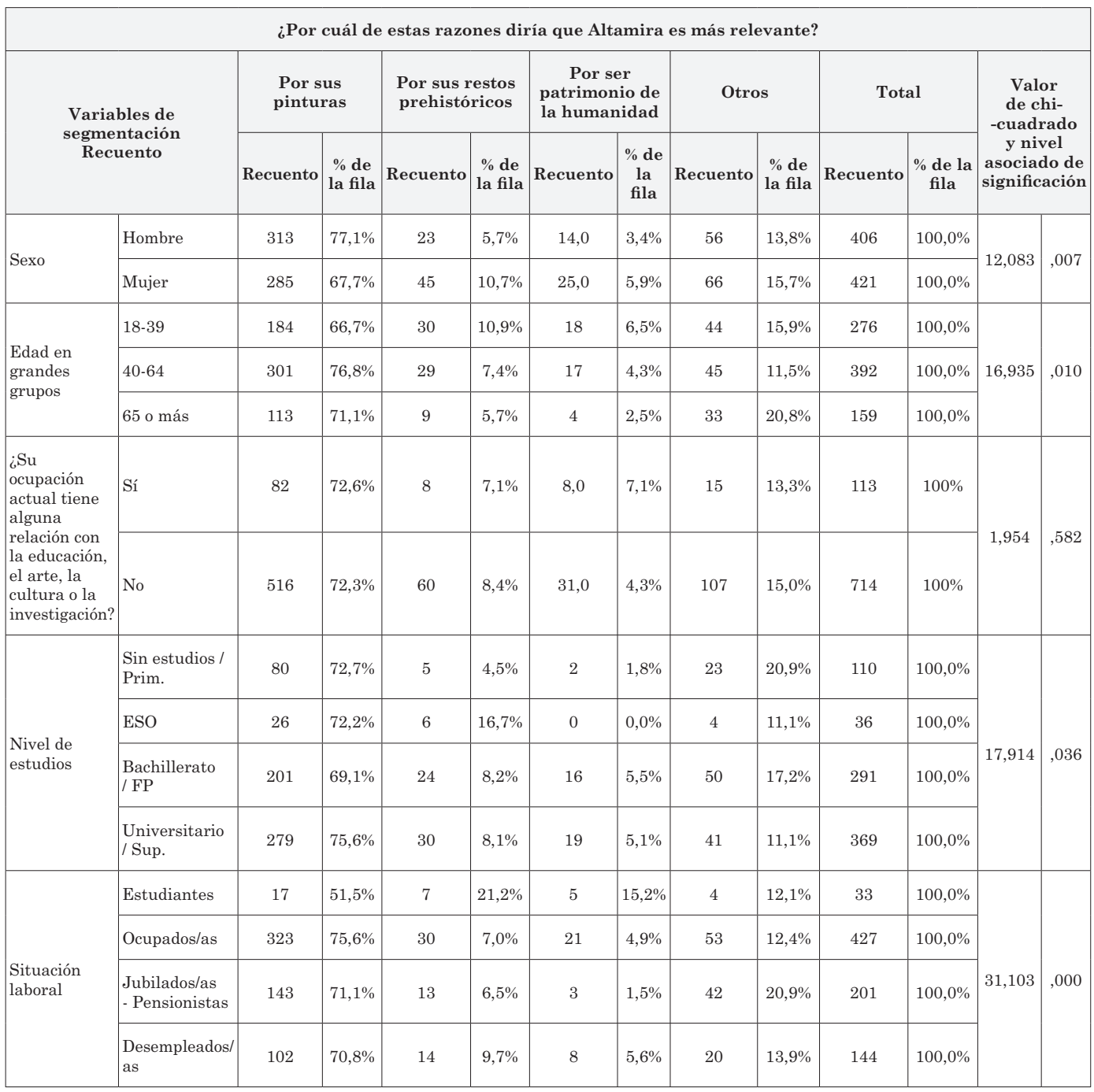

Fuente: Elaboración propia.

El CATPCA entre las variables de segmentación y de contraste (es decir, por qué Altamira es importante) discrimina en una primera dimensión un perfil sociodemográfico que asume claramente y aprecia la relevancia estética de las pinturas de Altamira. Dicho perfil se refiere a personas ocupadas con estudios universitarios o de bachillerato-FP, frente a otro que lo hace con menos intensidad, formado por personas jubiladas o pensionistas, de edad avanzada, sin estudios o con formación primaria (Figura 4). 
Figura 4: Gráfico de categorías conjuntas ("valor estético"- ¿Por cuál de estas razones diría que Altamira es más relevante? * variables de segmentación.

Autovalor $($ Total $)=3,701 /$ Alfa de Cronbach $($ Total $)=0,876$. Autovalor $($ Dimensión 1$)=2,392 /$ Alfa de Cronbach $($ Dimensión 1) $=0,698$.

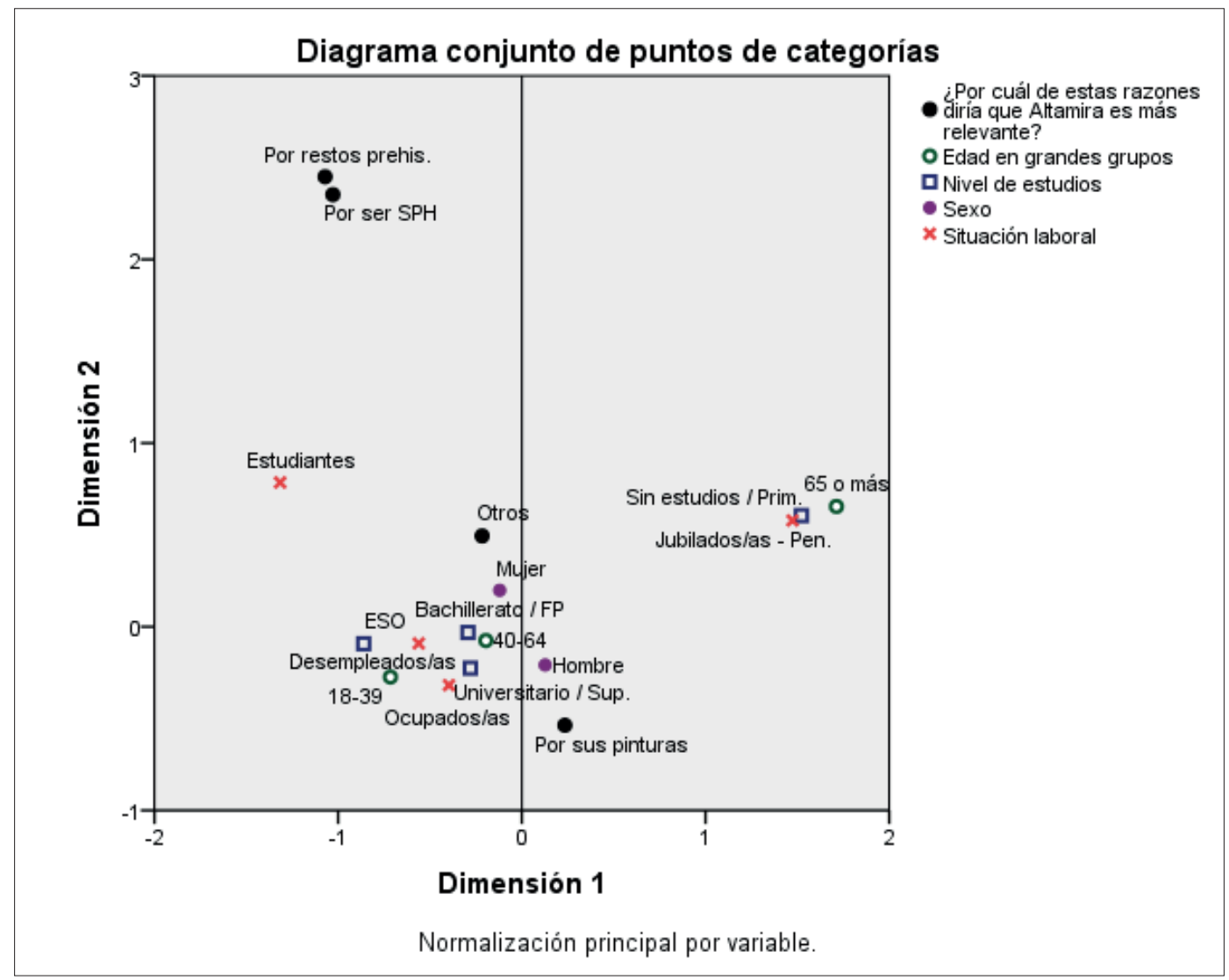

Fuente: Elaboración propia.

En definitiva, las percepciones estéticas de los visitantes resaltan la conexión entre el reconocimiento público de Altamira y sus pinturas prehistóricas. Al igual que ocurría con su valor de existencia, es el nivel educativo el que determina preferentemente el valor estético de Altamira: a mayores niveles de conocimiento y formación, más fácil resulta conectar el valor estético de las pinturas de Altamira con su importancia patrimonial, conexión que va más allá de la marca SPH. De hecho, los resultados de este estudio muestran que la declaración de Altamira como SPH no supone un factor determinante para visitantes o población local a la hora de construir la percepción contemporánea de este lugar, o al menos dicho factor está muy lejos de la capacidad atribuida a las pinturas. Esta asociación ocurre independientemente del perfil sociodemográfico de los visitantes y de la proximidad geográfica a Altamira para la población española.

Además, los resultados muestran un elevado nivel de satisfacción tras la visita a Altamira con 5,9 puntos de media en una escala del 1 al 7. Por lo tanto, la visita a la "Neo-Cueva" no merma el valor estético de Altamira, sobre todo entre el público visitante, quien tiene una comprensión consolidada de la importancia artística de las pinturas de Altamira, a pesar de no poder acceder a la versión original. Estos resultados relativizan el valor universal excepcional establecido por colectivos expertos a través de la declaración de SPH, coincidiendo en esta cuestión con el estudio de Tucker y Carnegie (2014). De hecho, a través de la comprensión de los factores que discriminan el valor estético o los sesgos perceptivos 
de actores no expertos, es posible evaluar la valoración social de este SPH, y los factores subyacentes que explican su capacidad de atracción como destino turístico y marca cultural.

\subsection{Valor económico}

El valor social de Altamira también está asociado con su valor económico. El complejo de Altamira atrae a un número significativo de visitantes y, por tanto, es un factor determinante a la hora de elegir Cantabria como destino turístico. En concreto, la duración media de la estancia de los visitantes de Altamira en esta región es de 4,6 noches, representando el 26\% de las pernoctaciones anuales en establecimientos turísticos cántabros (INE, 2013). Los costes relacionados con el alojamiento y la manutención representan la mayor parte del gasto total (63\%) de este colectivo. Igualmente, los gastos relacionados con el ocio, la cultura y el entretenimiento representan un $11 \%$ del total. En total, el gasto medio per cápita y por día es de 104,5 €. Estos datos han sido utilizados para estimar el impacto económico directo de Altamira en Cantabria, que asciende a $113 €$ millones en el año 2014. Esta cifra representó el 8,5\% del PIB turístico cántabro, y un 0,9\% del PIB total.

En definitiva, el gasto de la población visitante tiene un importante impacto en la economía regional $\mathrm{y}$, por tanto, el impacto generado por Altamira se traduce en una importante fuente de ingresos para la región cántabra y sus habitantes. A su vez, el valor económico está asociado claramente con la trascendencia sociocultural de este espacio patrimonial, lo que denota la necesidad de garantizar la conservación a largo plazo de la cueva, a la vez que promocionar de manera continua las visitas a este lugar. En este sentido, Altamira conforma un "imaginario cultural" y un "recurso operativo" para la dinamización de este espacio arqueológico, con implicaciones socioeconómicas para la comunidad local, siguiendo la terminología del estudio de Ross, Saxena, Correia y Deutz (2017).

\subsection{Valor de legado}

Las percepciones de los visitantes y la población española sobre la dimensión de legado, muestran que la cueva de Altamira es un activo patrimonial que debe preservarse para las generaciones futuras, cuestión ésta más importante que cualquier otra que incluya un posible escenario de reapertura. Primero, de la población española que conocía la existencia de la cueva (83\%), el 81,2\% también sabía que estaba cerrada al público. Igualmente, una amplia mayoría de las personas encuestadas (92,2\%) aceptan que la cueva permanezca cerrada para garantizar su conservación futura. Tercero, una mayoría de la población (55,3\%) también se muestra de acuerdo con el hecho de que su conservación futura sea costeada, impositivamente, por todos los españoles.

Asimismo, precisar que el conocimiento del cierre de la cueva al público es general en todas las NUTS españolas y en Cantabria, con porcentajes de respuestas afirmativas superiores al $87 \%$. Respecto al valor de legado, las disparidades territoriales no fueron lo suficientemente significativas como para alterar este alto grado de consenso $\left(\chi^{2}=6,031, \mathrm{p}>0.05\right)$. Así, la importancia del valor de legado es independiente de la región geográfica de residencia.

Además, se manifiesta un claro consenso entre la población encuestada sobre la necesidad de implementar medidas concretas de conservación para favorecer la sostenibilidad y gestión futura de la cueva de Altamira. Una mayoría significativa entiende que la cueva debería abrirse a "un número limitado de personas" (68,9\%), o acepta que debiera estar "cerrada al público" (17,4\%). Contrastando este valor de legado con los ítems de segmentación, aflora un amplio consenso alrededor de las actitudes/ categorías "proteccionistas" sobre el futuro de la cueva ("cerrada"/"abierta con límites"). Una variable destaca, nuevamente, sobre esta cuestión: el nivel educativo muestra una correspondencia claramente significativa con respecto al valor de legado. Así, la diferencia entre la formación de las personas encuestadas es la que determina la polaridad de opiniones sobre cómo preservar el «valor de legado" $\left(\chi^{2}=28,692 ; \mathrm{p}<.01\right)($ Tabla 3$)$. 
Tabla 3: Tabla de contingencia (valor de legado * variables
de segmentación). Fuente: elaboración propia.

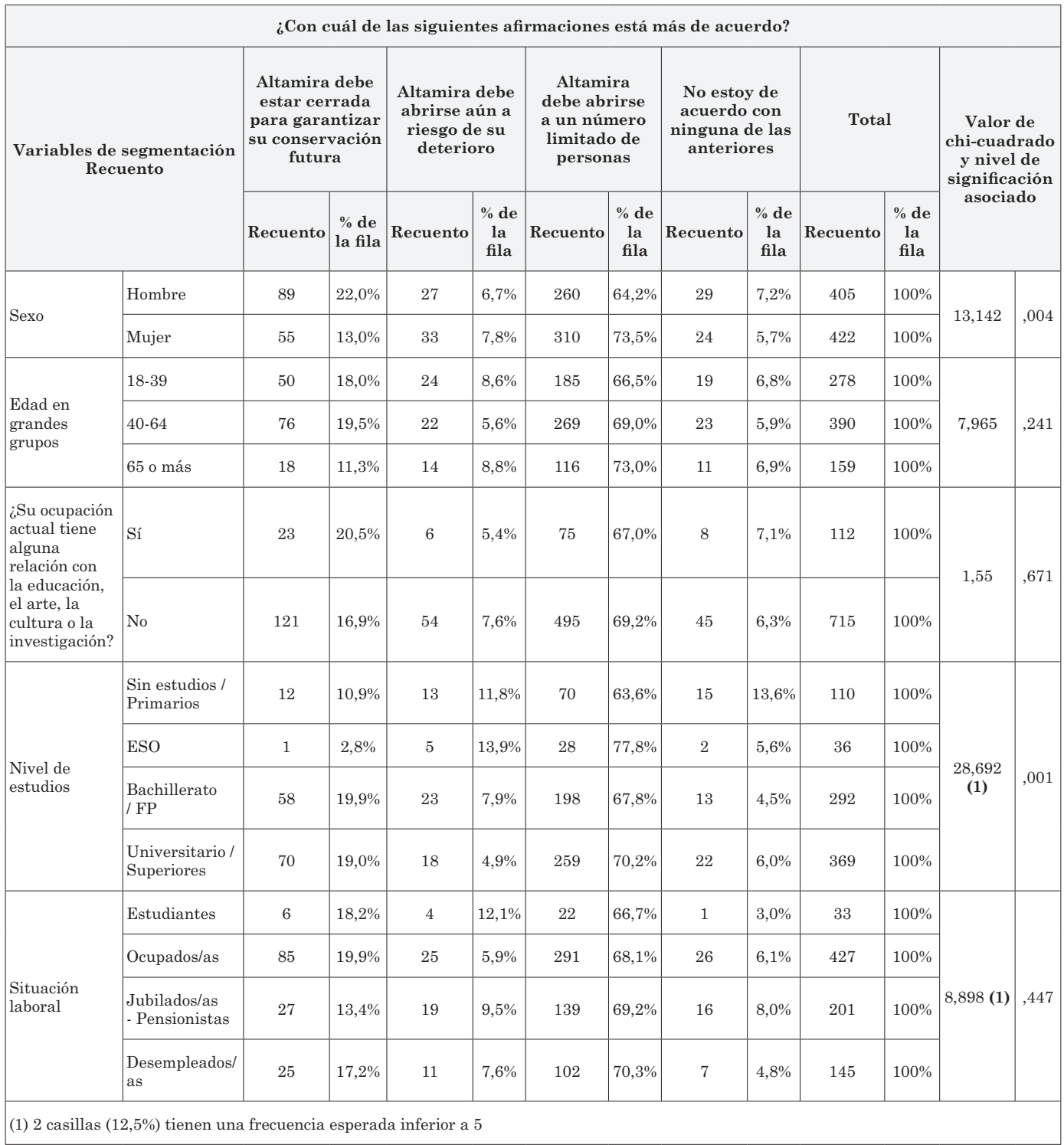

Examinando esta última evidencia mediante un ACS, se vuelve a constatar la importancia del nivel educativo de las personas encuestadas al evaluar la fortaleza del valor de legado. Por ejemplo, la mayor "intensidad proteccionista" se corresponde con un mayor nivel de educación, algo evidente a través del gráfico de dispersión (Figura 5). En éste se observa la proximidad espacial de los centroides de las categorías "Altamira tiene que estar cerrada" y la población con estudios "universitarios o superiores". 
Figura 5: Gráfico de categorías conjuntas ("valor de legado" * nivel de estudios). Inercia $($ Total $)=0,036$. Dimensión 1: inercia $=0,026$; proporción de inercia explicada $=0,741$.

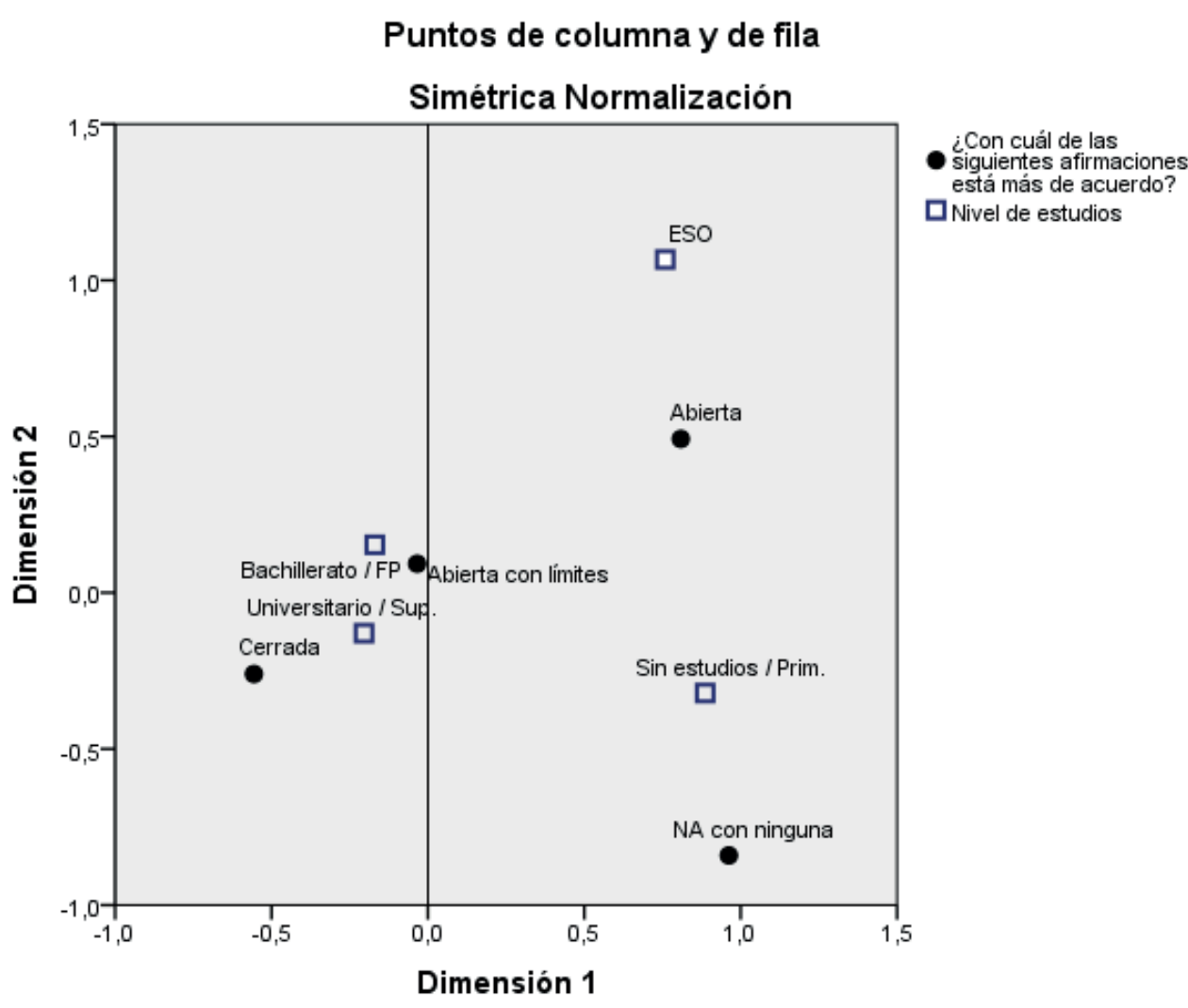

Fuente: Elaboración propia.

También podemos concluir que la aceptación del cierre de la cueva para garantizar su conservación futura fue muy elevada entre la población visitante. De hecho, el 63,8\% califica esta opción como "muy buena" y el 31,8\% como "buena". Es importante enfatizar que la mayoría de las personas visitantes que apoyan el cierre son también las más satisfechas con la "Neo-Cueva" y la visita al Museo. Tras la realización de un ANOVA, se observa la importancia del valor de legado entre el público visitante. Para una amplia mayoría, el cierre de la cueva no merma los grados de satisfacción con el conjunto museístico de Altamira; todo lo contrario, los incrementa y diferencia de modo significativo (Tabla 4). 
Tabla 4: Tabla de contingencia (valor de legado * variables de segmentación).

\begin{tabular}{|c|c|c|c|c|c|c|c|c|c|c|c|}
\hline \multirow[b]{2}{*}{$\begin{array}{l}\text { Variables } \\
\text { de } \\
\text { contraste }\end{array}$} & \multicolumn{6}{|c|}{$\begin{array}{c}\text { Motivos. Impresión que le produce: } \\
\text { Porque así se garantiza su conservación } \\
\text { futura }\end{array}$} & \multicolumn{2}{|c|}{ ANOVA } & \multicolumn{3}{|c|}{ Games-howell } \\
\hline & $\begin{array}{c}\text { Muy } \\
\text { mal } \\
(1)\end{array}$ & $\begin{array}{c}\text { Mal } \\
\text { (2) }\end{array}$ & $\begin{array}{c}\mathrm{Ni} \\
\text { bien } \\
\text { ni } \\
\text { mal } \\
(3) \\
\end{array}$ & Bien (4) & $\begin{array}{l}\text { Muy } \\
\text { bien } \\
(5)\end{array}$ & Total & $\mathbf{F}$ & Sig. & $\begin{array}{l}\text { Ejemplos de } \\
\text { relaciones } \\
\text { significativas }\end{array}$ & $\begin{array}{l}\text { Diferencia } \\
\text { de medias } \\
\text { (I-J) }\end{array}$ & Sig. $<0,01$ \\
\hline $\begin{array}{l}\text { Grado de } \\
\text { satisfacción } \\
\text { con la Neo- } \\
\text {-Cueva }\end{array}$ & 5,29 & 4,80 & 5,22 & 5,76 & 6,04 & 5,91 & 8,139 &, 000 & 4 у 5 &,- 283 & ,004 \\
\hline $\begin{array}{l}\text { Grado de } \\
\text { satisfacción } \\
\text { general con } \\
\text { respecto a } \\
\text { la visita al } \\
\text { Museo }\end{array}$ & 5,25 & 5,10 & 5,44 & 5,65 & 6,03 & 5,88 & 10,308 &, 000 & 4 y 5 &,- 384 & ,000 \\
\hline
\end{tabular}

Fuente: Elaboración propia.

Respecto a esta última evidencia, cabe señalar que la visita a Altamira es muy efectiva a la hora de reforzar el valor de legado mediante una experiencia de enseñanza-aprendizaje. De hecho, después de recorrer el museo, el $56,0 \%$ y el $24,5 \%$ de sus visitantes, respectivamente, entendieron "mucho" o "bastante" el porqué del cierre de la cueva. Además, tras la realización de un segundo ANOVA, se corrobora esta función didáctica del Museo en cuanto al valor de legado. Así, la mayoría de las personas que entendieron las razones por las cuales la cueva se encuentra cerrada, mostraron un grado de satisfacción con la visita al Museo y con la "Neo-Cueva" significativamente más alto que el de la minoría que no comprendió tales motivos (Tabla 5).

Tabla 5: Tabla de contingencia (valor de legado * variables de segmentación).

\begin{tabular}{|c|c|c|c|c|c|c|c|c|c|c|c|}
\hline \multirow{2}{*}{$\begin{array}{l}\text { Variables } \\
\text { de } \\
\text { contraste }\end{array}$} & \multicolumn{6}{|c|}{$\begin{array}{c}\text { Aumento de conocimientos: He aprendido } \\
\text { sobre la evolución humana }\end{array}$} & \multicolumn{2}{|c|}{ ANOVA } & \multicolumn{3}{|c|}{ Games-howell } \\
\hline & $\begin{array}{c}\text { Nada } \\
\text { (1) }\end{array}$ & $\begin{array}{l}\text { Poco } \\
(2)\end{array}$ & $\begin{array}{c}\text { Algo } \\
(3)\end{array}$ & $\begin{array}{l}\text { Bastante } \\
\quad(4)\end{array}$ & $\begin{array}{l}\text { Mucho } \\
(5)\end{array}$ & Total & $\mathbf{F}$ & Sig. & $\begin{array}{l}\text { Ejemplos de } \\
\text { relaciones } \\
\text { significativas }\end{array}$ & $\begin{array}{c}\text { Diferencia } \\
\text { de medias } \\
\text { (I-J) }\end{array}$ & $\begin{array}{c}\text { Sig. } \\
<0,01\end{array}$ \\
\hline \multirow{2}{*}{$\begin{array}{l}\text { Grado de } \\
\text { satisfacción } \\
\text { con la Neo- } \\
\text {-Cueva }\end{array}$} & \multirow{2}{*}{5,06} & \multirow{2}{*}{5,66} & \multirow{2}{*}{5,72} & \multirow{2}{*}{6,18} & \multirow{2}{*}{6,49} & \multirow{2}{*}{5,91} & \multirow{2}{*}{21,701} & \multirow{2}{*}{,000 } & $1 \mathrm{y} 4$ & $-1,122$ &, 001 \\
\hline & & & & & & & & & 1 y 5 & $-1,430$ & ,000 \\
\hline \multirow{2}{*}{$\begin{array}{l}\text { Grado de } \\
\text { satisfacción } \\
\text { general } \\
\text { con } \\
\text { respecto a } \\
\text { la visita al } \\
\text { Museo }\end{array}$} & \multirow[b]{2}{*}{4,86} & \multirow[b]{2}{*}{5,41} & \multirow[b]{2}{*}{5,77} & \multirow[b]{2}{*}{6,16} & \multirow[b]{2}{*}{6,45} & \multirow[b]{2}{*}{5,88} & \multirow[b]{2}{*}{34,981} & \multirow[b]{2}{*}{, 000} & $1 \mathrm{y} 4$ & $-1,292$ & ,000 \\
\hline & & & & & & & & & 1 y 5 & $-1,583$ & ,000 \\
\hline
\end{tabular}

Fuente: Elaboración propia.

El estudio del valor de legado nos permite plantear diferentes interpretaciones acerca del dilema sobre la promoción-protección de Altamira desde perspectivas no expertas, aportando nuevas ideas al debate sobre su futura reapertura o cierre. La principal conclusión de este análisis es que el nivel educativo es la variable sociodemográfica que más capacidad tiene de polarizar las opiniones sobre cómo mantener el valor de legado. De hecho, los niveles educativos más altos están vinculados a una mayor 
satisfacción con el complejo museístico, lo que nuevamente resalta la relevancia de este ítem para la comprensión del patrimonio cultural, su preservación y su interacción con las medidas de promoción turística. El valor de legado, asociado con un espacio patrimonial específico, juega un papel decisivo en la implementación de políticas de conservación y la gestión como marca de destino turístico, a la vez que promueve la integración del turismo con actividades económicas locales y un vínculo con sus residentes. Finalmente, según lo establecido por Craik (1997), el nivel educativo es un factor clave para abordar el turismo cultural y no sólo como una estrategia de marketing. La creación de una cultura del turismo que entienda los espacios patrimoniales y su apego a los mismos resulta fundamental para fomentar el VSP.

\section{Conclusiones}

La presente investigación abre una nueva vía de investigación teórica y metodológica al abordar la relación entre el VSP y la imagen de marca de SPH mediante el estudio de la dicotomía entre promoción y preservación entre diversos actores sociales. Para dilucidar esta cuestión se examinó el caso de la Cueva de Altamira (España), cuyos resultados de investigación muestran cómo aspectos sociales tales como los niveles de conocimiento y educación por parte de la población anfitriona pueden legitimar su interés social más allá de su declaración institucional, así como un valor de existencia, estético, económico y de legado. Así, cuanto mayores son los niveles de conocimiento y educación de una población o comunidad anfitriona de $\mathrm{SPH}$, mayor es la posibilidad de construcción de una imagen de marca en torno a estos espacios, superando estrategias de marketing a corto plazo. Paralelamente, cuanto mayor es el nivel educativo y el conocimiento de los visitantes sobre SPH, mayores son los niveles de satisfacción alcanzados durante la vista. Estas conclusiones resultan novedosas en el ámbito de los estudios del patrimonio y de turismo, destacando la importancia de analizar el VSP como constructo social y dinámico en la gestión patrimonial y turística de SPH.

Las consecuencias normativas y aplicadas contribuyen a una mejor toma de decisiones políticas respecto a SPH, donde interactúan diferentes dimensiones valorativas y confluyen problemas de escala y población (de qué comunidades estamos hablando, qué agentes las constituyen y cuán diversos son sus capitales e intereses), así como de proceso (cómo evolucionan estos elementos en función del propio desarrollo de los enclaves patrimoniales). Esto significa que la forma de analizar, modelizar y comprender los fenómenos valorativos asociados a los procesos patrimoniales tiene que atender a una diversidad empírica y metodológica importante. Para poder diseñar y ejecutar planes patrimoniales sostenibles e integrados con las políticas turísticas y de desarrollo comunitario debemos reconocer la existencia de los procesos sociales valorativos en torno al patrimonio, es decir, el valor social del patrimonio en toda su complejidad, algo más que una cuestión de ingresos monetarios y expectativas de visita. Y para que esto sea efectivo es preciso posibilitar una investigación transdisciplinar que dé sentido al análisis de dichos procesos. Sólo esta investigación puede proporcionar los datos necesarios para respaldar y orientar políticas de gestión y fomento turístico hacia un horizonte de sostenibilidad y de racionalidad en el acceso y uso de los recursos patrimoniales en base a su genérico valor social. Futuras investigaciones deberían profundizar en otros aspectos del valor social del patrimonio desde perspectivas diversas, dejando atrás concepciones del patrimonio ancladas en su dimensión material y construida que limitan la amplitud del debate alrededor del complejo y conflictiva entente entre turismo, patrimonio, economía y comunidad.

\section{Bibliografía}

Adie, B. A., Hall, C. M. y Prayag, G. (2017). World Heritage as a placebo brand: a comparative analysis of three sites and marketing implications. Journal of Sustainable Tourism, 26(3), 399-415.

Alonso González, P. (2016). Patrimonio y ontologías múltiples: hacia la co-producción del patrimonio cultural. En C. Gianotti (Ed.), Patrimonio y multivocalidad. Teoría, práctica y experiencias en torno a la construcción del conocimiento en Patrimonio (pp. 179-198). Montevideo: CSIC - UdelaR.

Alonso González, P. (2017). El Antipatrimonio: Fetichismo y dominación en Maragatería (España). Madrid: CSIC.

Alonso González, P., Macías Vázquez, A. y Fernández Fernández, J. (2017). Governance Structures for the Heritage Commons: La Ponte-Ecomuséu-Ecomuseum of Santo Adriano, Spain. En P. Gould y A. 
Pyburn (Eds.), Collision or Collaboration: archaeology encounters economic development (pp. 153-170). Cham: Springer.

Araoz, G. F. (2011). Preserving heritage places under a new paradigm. Journal of cultural heritage management and sustainable development, 1(1), 55-60.

Barreiro, D. y Criado-Boado, F. (2015). Analizando el Valor Social de Altamira. Revista PH, 87, 108-127.

Barreiro, D., Criado-Boado, F., Téllez Delgado, V., Sánchez Carretero, C., Parga Dans, E. y Sánchez Martín, R. (2018). Las tres vidas de Altamira y el futuro. Sémata, 30, 479-502.

Benito Del Pozo, P. y Alonso González, P. (2012). Industrial Heritage and Place Identity in Spain: From Monuments to Landscapes. Geographical Review, 102(4), 446-464.

Bertacchini, E., Liuzza, C. y Meskell, L. (2017). Shifting the balance of power in the UNESCO World Heritage Committee: an empirical assessment. International journal of cultural policy, 23(3), 331-351.

Bourdeau, L., Gravari-Barbas, M. y Robinson, M. (2018). World heritage, tourism and identity: inscription and co-production. London: Routledge.

Cartailhac, É. (1902). Les cavernes ornées de dessins. La grotte d'Altamira, Espagne. Mea culpa d'un sceptique. L'anthropologie, 13(1), 41-68.

Carter, L. S., Jolliffe, L. y Baum, T. (2001). Heritage tourism and world heritage sites the case of Newfoundland. Tourism Recreation Research, 26(1), 113-116.

Craik, J. (1997). The culture of tourism. En C. Rojek y J. Urry (Eds.), Touring cultures (pp. 113-136). London: Routledge.

Chen, C.-F. y Chen, F.-S. (2010). Experience quality, perceived value, satisfaction and behavioral intentions for heritage tourists. Tourism management., 29-35(1), 29.

Darvill, T. (1994). Value systems and the archaeological resource. International Journal of Heritage Studies, 1(1), 52-64.

Díaz-Andreu, M. (2017). Heritage Values and the Public. Journal of Community Archaeology \& Heritage, 4(1), 2-6.

González-Ruibal, A., Alonso González, P. y Criado-Boado, F. (2018). Against reactionary populism: towards a new public archaeology. Antiquity, 92(362), 507-515.

Goulding, C. (2000). The commodification of the past, postmodern pastiche, and the search for authentic experiences at contemporary heritage attractions. European Journal of Marketing, 34(7), 835-853.

Graham, B., Ashworth, G. y Tunbridge, J. (2016). A geography of heritage. London; New York: Routledge.

Hair, J., Black, W. C., Babin, B. J. y Anderson, R. (2010). Multivariate data analysis: International version. New Jersey: Pearson.

Hall, C. M. y Piggin, R. (2002). Tourism business knowledge of World Heritage sites: A New Zealand case study. International Journal of Tourism Research, 4(5), 401-411.

ICOMOS. (2019). European quality principles for EU-funded interventions with potential impact upon cultural heritage. Paris.

Icomos Australia. (1999 [1979]). The Burra Charter and guidelines to the Burra Charter. Canberra: Icomos. INE. (2013). Hotel Occupancy Survey (HOS). Madrid: Spanish National Statistic Institute.

Jansen-Verbeke, M. (2016). Foreword. En M. D. Alvarez, F. M. Go, y A. Yuksel (Eds.), Heritage tourism destinations: preservation, communication and development (pp. xii-xiv). Wallingford: CABI.

Joaristi, L. y Lizasoain Hernández, L. (2000). Análisis de correspondencias. Madrid; Salamanca: La Muralla; Hespérides.

Jones, S. (2017). Wrestling with the social value of heritage: problems, dilemmas and opportunities. Journal of Community Archaeology \& Heritage, 4(1), 21-37.

Martin-Rios, C. y Parga-Dans, E. (2016a). The early bird gets the worm, but the second mouse gets the cheese: Non-technological innovation in creative industries. Creativity and innovation management, $25(1), 6-17$

Martin-Rios, C. \& Parga-Dans, E. (2016b). Service response to economic decline: Innovation actions for achieving strategic renewal. Journal of business research, 69(8), 2890-2900.

Mason, R. y Avrami, E. (2002). Heritage values and challenges of conservation planning. En J. Teutonico y G. Palumbo (Eds.), Management planning for archaeological sites (pp. 13-26). Los Angeles: Getty Institute Loyola University.

Michelson, A. y Paadam, K. (2016). Destination branding and reconstructing symbolic capital of urban heritage: A spatially informed observational analysis in medieval towns. Journal of destination marketing \& management, 5(2), 141-153.

Parga Dans, E. (2019). Heritage in danger. The collapse of commercial archaeology in Spain. Archaeological Dialogues, 26(2), 111-122. doi:10.1017/S1380203819000217 
Parga Dans, E. y Alonso González, P. (2017). The Altamira controversy: Assessing the economic impact of a world heritage site for planning and tourism management. Journal of cultural heritage, 30, 180-189.

Parga Dans, E. y Alonso González, P. (2019). Sustainable tourism and social value at World Heritage Sites: Towards a conservation plan for Altamira, Spain. Annals of Tourism Research, 74, 68-80.

Parga Dans, E. y Alonso González, P. (2020). The Unethical Enterprise of the Past: Lessons from the Collapse of Archaeological Heritage Management in Spain. Journal of Business Ethics. https://doi. org/10.1007/s10551-020-04504-6

Parga-Dans, E., Barreiro, D. y Varela-Pousa, R. (2016). Isomorphism and legitimacy in Spanish contract archaeology: the free-fall of an institutional model and the caveat of change. International journal of heritage studies, 22(4), 291-301.

Parkinson, A., Scott, M. y Redmond, D. (2016). Defining “Official” Built Heritage Discourses within the Irish Planning Framework: Insights from Conservation Planning as Social Practice. European Planning Studies, 24(2), 277-296.

Petr, C. (2009). Fame is not always a positive asset for heritage equity! Some clues from buying intentions of national tourists. Journal of Travel and Tourism Marketing, 26(1), 1-18.

Poria, Y., Reichel, A. y Cohen, R. (2013). Tourists perceptions of World Heritage Site and its designation. Tourism management, 35, 272-274.

Poulios, I. (2010). Moving Beyond a Values-Based Approach to Heritage Conservation. Conservation and Management of Archaeological Sites, 12(2), 170-185. doi:10.1179/175355210X12792909186539

Prats, L. (2003). Patrimonio+ Turismo=i Desarrollo? PASOS, 1(2), 127-136.

Prats, L. (2011). La viabilidad turística del patrimonio. PASOS, 9(2), 249-264.

Ramires, A., Brandao, F. y Sousa, A. C. (2018). Motivation-based cluster analysis of international tourists visiting a World Heritage City: The case of Porto, Portugal. Journal of Destination Marketing and Management, 8, 49-60.

Ross, D., Saxena, G., Correia, F. y Deutz, P. (2017). Archaeological tourism: A creative approach. Annals of Tourism Research, 67, 37-47.

Ryan, J. y Silvanto, S. (2010). World Heritage Sites: The Purposes and Politics of Destination Branding. Journal of Travel \& Tourism Marketing, 27(5), 533-545.

Santa-Cruz, F. G. y López-Guzmán, T. (2017). Culture, tourism and World Heritage Sites. Tourism Management Perspectives, 24, 111-116.

Schabereiter-Gurtner, C., Saiz-Jimenez, C., Piñar, G., Lubitz, W. y Rölleke, S. (2002). Altamira cave Paleolithic paintings harbor partly unknown bacterial communities. FEMS Microbiology Letters, 211(1), 7-11. doi:10.1111/j.1574-6968.2002.tb11195.x

Tucker, H. y Carnegie, E. (2014). World heritage and the contradictions of 'universal value'. Annals of Tourism Research, 47, 63-76.

Viu, J. M., Fernández, J. R. y Caralt, J. S. (2008). The impact of heritage tourism on an urban economy: the case of Granada and the Alhambra. Tourism Economics, 14(2), 361-376.

\section{Notas}

Todos los informes y datos brutos generados por este proyecto están disponibles en http://digital.csic.es/handle/10261/112860

Recibido:

$21 / 06 / 2020$

Reenviado:

$27 / 09 / 2020$

Aceptado:

$29 / 09 / 2020$

Sometido a evaluación por pares anónimos 